\title{
Metacarpophalangeal Joint
}

National Cancer Institute

\section{Source}

National Cancer Institute. Metacarpophalangealjoint. NCI Thesaurus. Code C33106.

The spheroid synovial joints between the metacarpals and the proximal phalanges of the hand. 